\title{
Analysis and Modeling of Power Consumption Modes of Tunnelling Complexes in Coal Mines
}

\author{
Vadim Petrov ${ }^{1}$, Alhidin Sadridinov ${ }^{1}$, and Alexandr Pichuev ${ }^{1, *}$ \\ ${ }^{1}$ National University of Science and Technology MISiS, 119049, 4 Leninsky av., Moscow, Russia
}

\begin{abstract}
The technological processes of mining enterprises are largely energy-intensive; therefore, studying the modes of power consumption in different sites of a mining enterprise is a relevant task, as it makes it possible to reduce current costs. The article presents the results of an experimental study of the dynamics of changes in the specific power consumption depending on per-shift indicators of extracted rock volume and the rate of mine workings penetration. The analysis of geological, technological and organizational factors affecting the efficiency of mining operations in coal mines is performed. Energy technological profiles and recommendations for assessing sustainable levels of power consumption by mechanized tunnelling complexes are given. Dynamic and predictive models of power consumption have been developed taking into account the main time trends and additive components within the limits that ensure a steady level of power consumption. Special recommendations on improving the efficiency of power consumption during mining operations are given.
\end{abstract}

\section{Introduction}

The efficiency of mining enterprises is determined by the technical level of mechanization and automation of mining technological processes. In the conditions of developing market economy, the main requirements for mining equipment are increasing of operational efficiency and safety, reducing the metal consumption of machines and the energy intensity of rock destruction, reducing the load of mining operations on the environment, etc. $[1,2$, 3].

The intensification of mining in promising mines due to the technical re-equipment of heading and tunnelling complexes requires significant changes in the conduct of preparatory and mining operations. First, this concerns the progressive combine method, because the level of combine tunnelling in leading coal mines ranges from 72 to $98 \%$.

Mining workings tunnelling (MWT) in the conditions of coal mines are currently being developed intensively both in terms of increasing the volume of work performed and the rate of the workings' drivage, which is reflected in the increase in the energy intensity of technological processes and the amount of power consumed.

\footnotetext{
*Correspondent author: allexstone@mail.ru
} 
In accordance with the Long-Term Program for the Development of the Russian Coal Industry for the Period Until 2030 (LP-2030), widespread introduction of energy and resource-saving technologies in the field of coal mining is envisaged on the basis of deep modernization of the industry in the field of digitalization, automation, power and resources saving, etc. $[4,5,6]$.

One of the solutions to the problem of increasing the energy efficiency of MWT in coal mines is to ensure the stable operation of tunnelling complexes in accordance with the technological scheme.

The analysis showed that in the process of MWT conducting, there were violations of the operating modes of tunnelling complexes for both technological, technical and organizational reasons $[7,8]$. The management of mining processes can be synchronized through the organization of work based on the implementation of appropriate control algorithms.

\section{Material and Methods}

The aim of this work was to analyze and simulate the dynamics of power consumption in mining complexes and to evaluate the energy efficiency of mining operations in coal mines.

To achieve this goal, the task was set to develop dynamic models of electrical profiles in coal mines, allowing to take into account technological solutions, mining and geological conditions and organizational factors of production.

The analysis of the technical characteristics of the tunnelling machines and complexes that are commercially available on the world market and their operating modes has shown that the main directions associated with improving the energy efficiency of mining operations are focused on increasing the power supply and productivity of mining machines. This progress is carried out due to the transition to combines of medium (35-50 tons, 100-160 kW) and heavy types (up to 100-150 tons, up to $600-900 \mathrm{~kW}$ ), providing drivage of mine workings with a cross section of up to $40-45 \mathrm{~m}^{2}$, destruction of rocks with ultimate uniaxial compression strength up to $140-150 \mathrm{MPa}$, and having technical productivity up to $26-30 \mathrm{~m}^{3} / \mathrm{hr}[7,9]$.

The most optimal for analyzing the efficiency of power consumption is to present the dependences of the technological and specific power consumption in the form of multifactor (three-dimensional) models of the following type (1):

$$
W=f\left(Q_{1}, Q_{2}\right) \text { and } \omega=f\left(Q_{1}, Q_{2}\right)
$$

where: $W, \omega$ - respectively, the technological and specific power consumption for tunnelling;

$Q_{1}, Q_{2}$ - respectively, the productivity in terms of the volume of extracted rock mass (tons) and in terms of the running linear mine working (meters).

If one of the parameters is assumed to be discrete (i.e., constant at given intervals), then we can construct a two-dimensional model that represents the projection of the function onto the plane (see Fig. 1). In this case, for this projection, the so-called normalized characteristics are obtained that reflect the nature of the change in the desired function, if one of the arguments is a fixed constant and the second argument is a variable. Such a model is an energy-and-technology profile or cross-section [7].

Based on the results of the analysis of energy-and-technological profiles for the tunnel sections, the dependences of the changes in the technological and specific power consumption on the productivity of these sections in terms of the amount of extracted rock mass, running meters of workings of rock and coal were determined. This allows determining the ranges of changes in power consumption indicators depending on the shift 
capacity relative to its stable level and establish boundary values in accordance with the criteria of energy efficiency $[10,11,12]$.

The analysis of the dynamics of power consumption for each production site is carried out with the aim of establishing a general trend of the actual and specific power consumption and its subsequent comparison with planned (normalized) indicators. At the same time, the analysis of the causes of deviations from the general trend, including additive interference having a random nature, is performed.

Based on the determination of the stable operation levels of tunnelling mechanized complexes (TMC), as well as the study of the dynamics of power consumption, a predictive power consumption model is proposed. Its distinguishing feature is that it takes into account random processes of deviation from a stable level of power consumption (additive interference) associated with a violation of the technological process. The proposed algorithm for calculating the energy characteristics and energy technology profiles allows justifying and developing the energy efficiency management system taking into account their probabilistic nature $[13,14]$.

To implement the predictive model of energy flows taking into account the additive component, it is proposed to implement a time trend, the distinguishing feature of which is its limitation within the standard deviation.

In the work, a time series forecasting model is proposed, consisting of the $T(t)$ trend and the additive component $A(t)$ for the daily values of the $\omega$ indicator:

$$
\omega(t)=T(t)+S_{A(t)}
$$

where a linear function is used as a trend: $T(t)=\bar{\omega} \pm b \cdot t$.

The additive component (interference) is random. To model it, a probabilistic approach is used. In the case when $A(t)$ (deviation from the trend) obeys the normal distribution law and has a standard deviation $S_{A(t)}$, the random noise obeys the "three sigma rule" and is determined by the formula (3):

$$
S_{A(t)}=\left(\frac{1}{n-2} \sum_{t=1}^{n}[A(t)-\bar{A}(t)]^{2}\right)^{0,5}
$$

where: $n$ - the length of the range;

$\bar{S}_{A(t)}$ - interference average level;

$A(t)$ - deviation from the trend.

At the preliminary stage, the average shift productivity indicators of the sites were determined by the volume of extracted rock mass $Q_{l}(\mathrm{t})$, running meters of mining workings $Q_{2}(\mathrm{~m})$, as well as by the shift power consumption $W(\mathrm{kWh})$ and its specific consumption $\omega_{1}(\mathrm{kWh} / \mathrm{t})$ and $\omega_{1}(\mathrm{kWh} / \mathrm{m})$.

\section{Results and Discussion}

As a result of the analysis of indicators of annual productivity and technological power consumption in MWT, the following was established.

The range of changes in the indicators for the specific power consumption relative to the rock mass $\omega_{l}$ and relative to the drivage $\omega_{l}$ has a wide range of values, because direct extraction of the rock mass as part of the technological process is determined by its volume, rock density, degree of loosening and fullness of loading of the bucket or loading machine's feeding table. 
The analysis of energy-and-technological characteristics for various shifts showed that the main parameters largely depend on the level of qualification, the degree of organization and compliance with the planned performance indicators. This allows us to make operational adjustments to the maintenance of MWT. Moreover, the zone of optimal power consumption for stable modes for TMC is determined by the correlation ellipse for the technological power consumption [7].

To assess the actual specific power consumption for MWT, it is proposed to use the energy technology profiles presented in Fig. 1 and 2.

Since the initial parameter is the planned indicator of power consumption, then in accordance with it the optimal levels of power consumption for the TMC are determined. Exceeding these indicators shows an increase in power consumption and a drop in productivity. A decrease in these indicators shows an increase in wear of the cutting mechanism and the need to stop MWT for unscheduled repairs and maintenance.

The analysis of the dynamics showed that there are stable levels of specific power consumption. Deviations from them in the range exceeding $\sigma$ (standard deviation) lead to an excessive consumption of electricity or to an increase in the likelihood of stopping the MWT for unscheduled maintenance or repair.

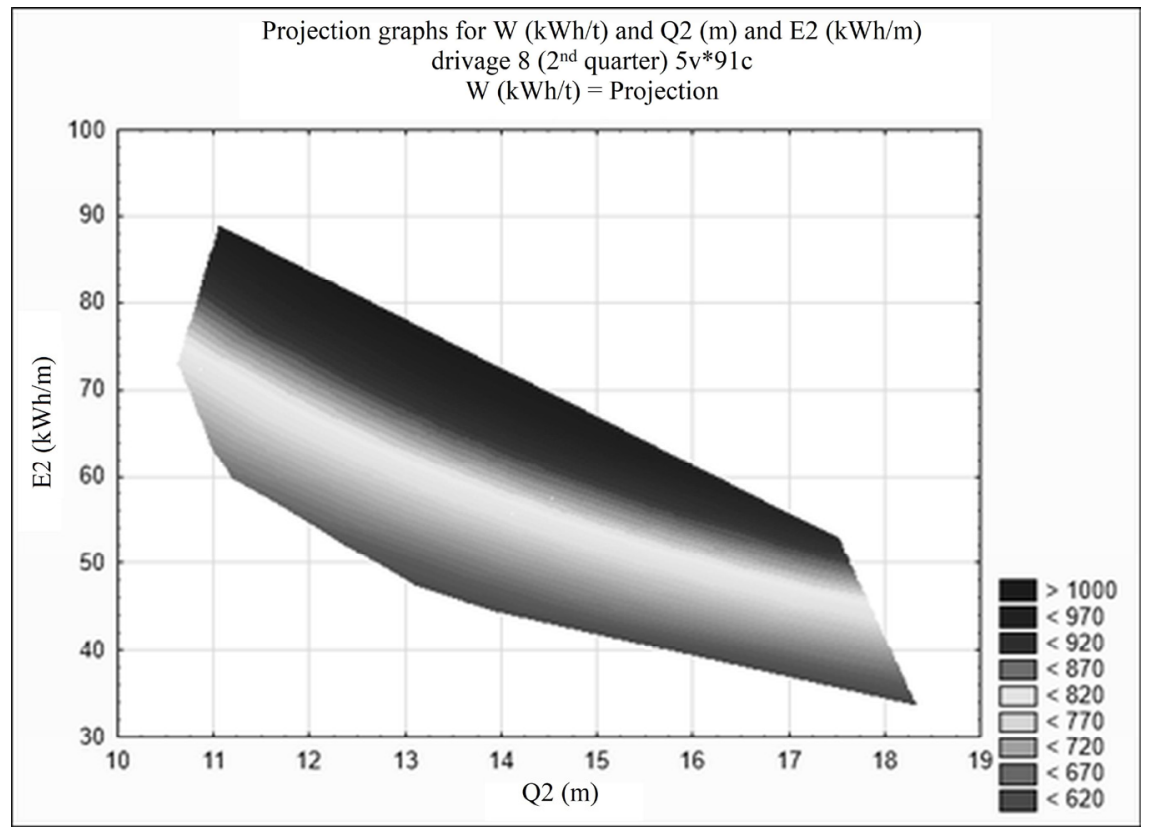

Fig. 1. Energy technology profiles of specific power consumption $E_{2}(\mathrm{kWh} / \mathrm{t})$ depending on $Q_{2}(\mathrm{~m})$ and $\omega_{2}(\mathrm{kWh} / \mathrm{m})$.

The graph of changes in the daily specific power consumption of the tunnelling site is shown on Fig. 3 as an example. The overall trend for the quarter is described by a linear dependence $\omega=61.7-0.046 t$. Analysis shows that the range of change for $\omega(t)$ indicates significant deviations from the general trend and exceeds the recommended limits corresponding to the stable operation of the MWT. 


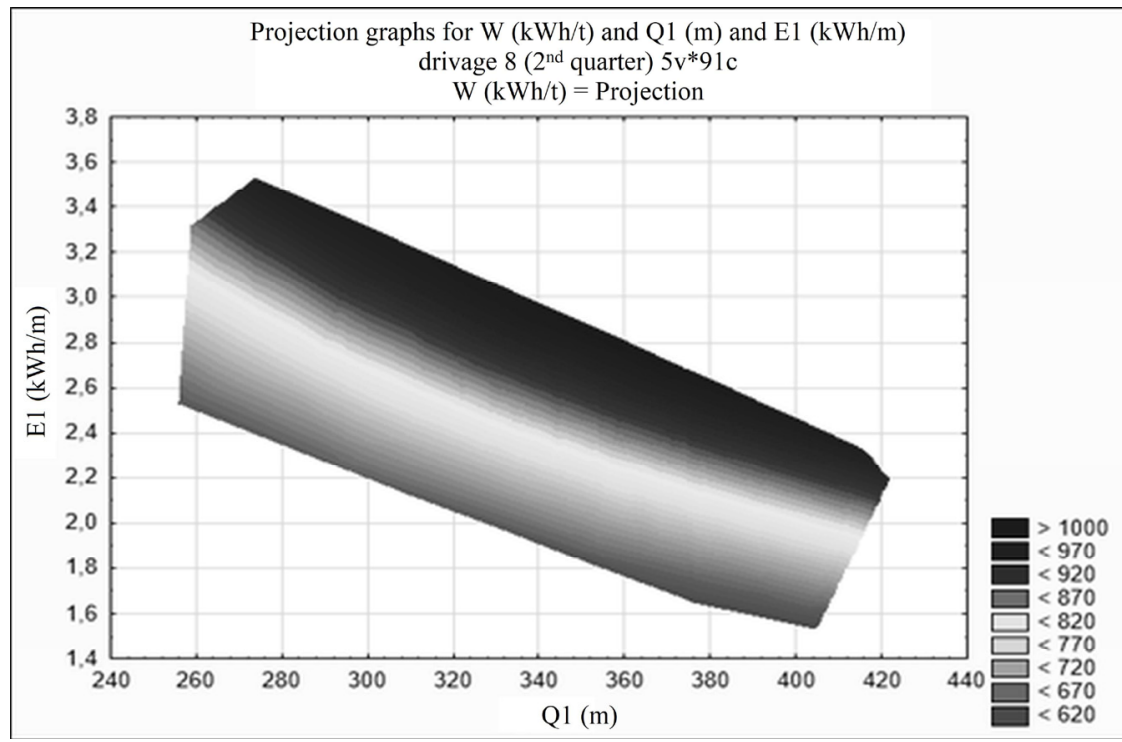

Fig. 2. Energy technology profiles of specific power consumption $E_{l}(\mathrm{kWh} / \mathrm{t})$ depending on $Q_{1}(\mathrm{~m})$ and $\omega_{1}(\mathrm{kWh} / \mathrm{m})$.

A predictive model of power consumption, obtained as a result of exponential smoothing and consisting of a time trend taking into account additive interference, which is a deviation within $\pm \Delta \varepsilon$, is shown in Fig. 4 . The forecast model, based on the quarterly schedule, is designed for 10 days with a lag of 12 for fixed indicators.

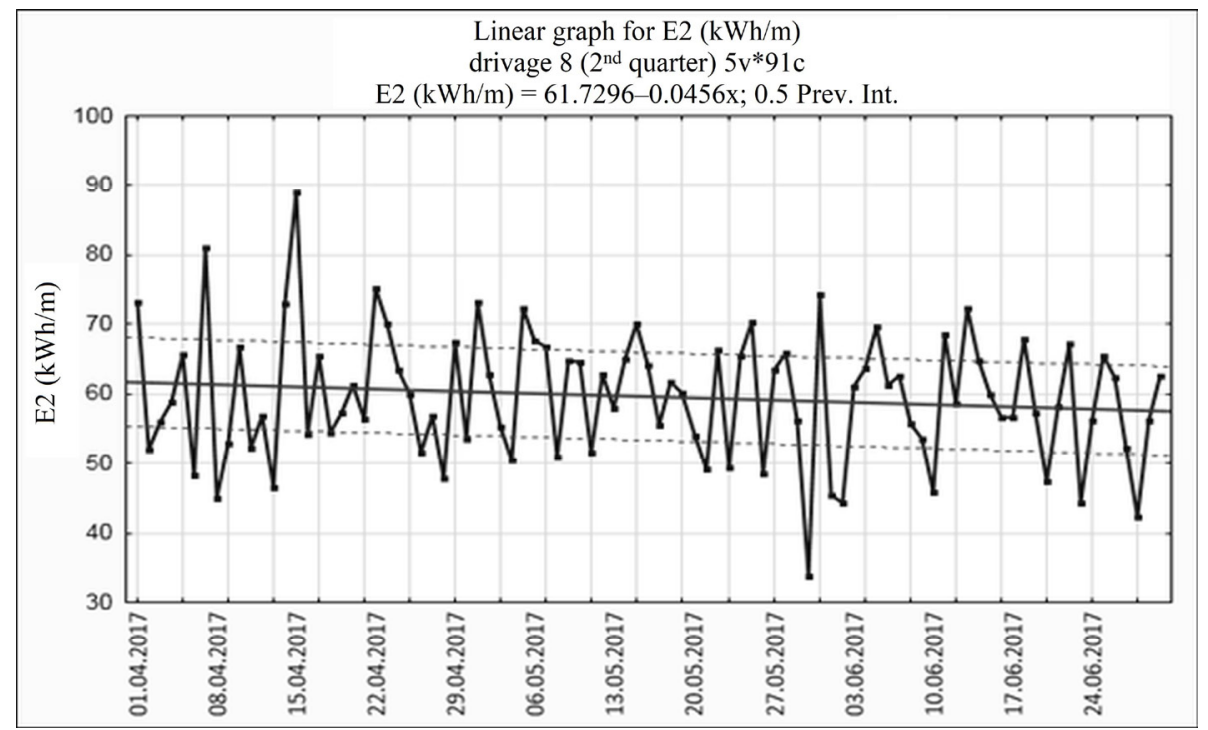

Fig. 3. Dynamics of specific power consumption $\omega=61.7-0.046 t$ (common trend). 


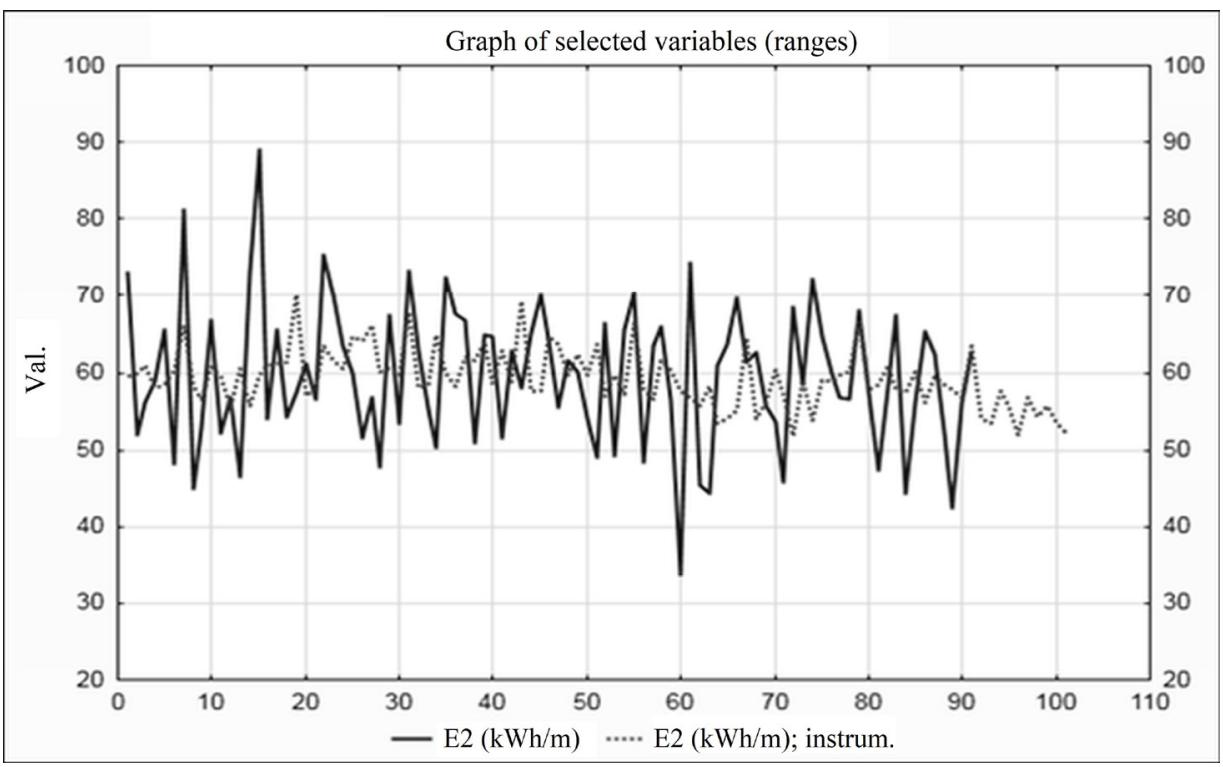

Fig. 4. Predictive model $\omega=61.7-0.046 t \pm \Delta \varepsilon$, where $\Delta \varepsilon=8.6$ - additive component.

\section{Conclusion}

As a result of the research, the following statements were made.

1. The energy flow indicators have a fairly wide range of variation, therefore, the zone of optimal stable operation of the TMC should be determined taking into account permissible deviations from the normal operating mode.

2. The reasons for the absolute indicators of power consumption outside the acceptable range are excess of the speed of workings' drivage by individual teams during the shift, violation of the overall cross-section of the mine, a sharp change in the geological characteristics of soils, loss of time to eliminate accidents on technological equipment, organizational reasons associated with violation of the technological process of tunnelling.

3. As a result of the regression analysis, energy-and-technological profiles of energy characteristics were obtained to assess the effectiveness of tunnelling operations.

4. Dynamic models taking into account general trends and additive components for determining energy efficiency indicators for MWT are developed. The obtained dynamic models are the basis for predicting the level of power consumption, substantiating regulatory indicators, as well as implementing power management algorithms

5. Practical recommendations for improving operational energy efficiency, taking into account the technical conditions for tunnelling at coal mines, include the following.

- for rock loading machines - ensuring the quality of face preparation in accordance with the categoricity of the mine, mining and geological conditions, the process scheme of drilling and blasting works and the blasting pattern in order to prevent the appearance of bulk rock pieces or their hanging, as well as exceeding the cross-section of working in the rough;

- for tunnelling combines of selective action - selection of parameters of the mode of destruction taking into account the degree of abrasiveness and permissible limits of rock strength for uniaxial compression and tension, in order to reduce wear of the rock-breaking tool, change its geometry and dynamic forces acting on the combine; 
- the increase of operational productivity due to timely execution and reduction of time spent on auxiliary operations, time to repair failures, downtime due to operational, organizational and technical reasons.

\section{References}

1. S. Lu, Advanced Materials Research, 482-484, 1490-1494 (2012) DOI: 10.4028/www.scientific.net/AMR.482-484.149

2. M. Bevilacqua, F. E. Ciarapica, C. Diamantini, D. Potena, International Journal of RF Technologies: Research and Applications, 8:3, 105-122 (2017) DOI: 10.3233/RFT17167

3. V. Figueiredo, F. Rodrigues, Z. Vale, J. B. Gouveia, IEEE Transactions on Power Systems, 20:2, 596-602 (2005) DOI: 10.1109/TPWRS.2005.846234.

4. International Standard ISO 13600 Technical energy systems. Basic concepts. First edition 1997-11-15 (Rosstandart, Moscow, 1997)

5. A. Verl, E. Abele, U. Heisel, A. Dietmair, P. Eberspächer, R. Rahäuser, S. Schrems, S. Braun, Proceedings of the 18th CIRP International Conference on Life Cycle Engineering, 341-342 (2011). DOI: 10.1007/978-3-642-19692-8-59

6. A. G. Zakharova, Gornyi Zhurnal, 2, 79-82 (2017) DOI: 10.17580/gzh.2017.02.15

7. A. V. Pichuev, Energy Efficiency of mining operations (LAP LAMBERT Academic Publishing, Saarbrücken, 2017)

8. Yu. V. Shevyrev, Gornyi Zhurnal, 2, 171-178 (2020) DOI: 10.25018/0236-1493-20202-0-

9. A. B. Zhabin, An. V. Polyakov, Al. V. Polyakov, V. V. Murashov, Gornyi Zhurnal, 12, 78-82 (2016). DOI: 10.17580/gzh.2016.12.16

10. T. Zhang, R. N. Taylor, G. Zheng, J. Sun, Q. Fan, Y. Diao, H. Zhou, Computers and Geotechnics, 104, 152-166 (2018). DOI: 10.1016/j.compgeo.2018.08.015

11. D. Dias, R. Kastner, Engineering Geology, 152:1, 17-25 (2013). DOI: 10.1016/j.enggeo.2012.10.002.

12. F. Draganescu, M. Gheorghe, C. V. Doicin, Journal of Materials Processing Technology, 141:1, 9-15 (2003). DOI: 10.1016/S0924-0136(02)00930-5

13. V. Y. Beglyakov, V. V. Aksenov, I. K. Kostinets, A. A. Khoreshok, Mining science and technology, 4, 23-30 (2017). https://doi.org/10.17073/2500-0632-2017-4-23-28

14. V. V. Gabov, D. A. Zadkov, Eurasian Mining, 1, 37-40 (2016). DOI: 10.17580/em.2016.01.06

15. G. I. Bobokin, D. M. Shprekher, E. B. Kolesnikov, Parameter control and forecast for electric drive parameters of cutter-loader (International Conference on Industrial Engineering, Applications and Manufacturing (ICIEAM), Saint Petersburg, 2017) DOI: 10.1109/ICIEAM.2017.8076303 